\title{
Comparing Outcomes of Transurethral Resection of the Prostate in Men with Greater Than or Less Than 100 cc Prostate Volume: A Single-Centre Study
}

\author{
(1) Munad Khan1, (1) Alexander L. Nesbitt1,2, (1) Ajanthan Loganathan1, (1) Stefan Antoniou1,3,4, (1) Garrath Evans 1,3,4, \\ (D) Philip Smith1,3,4, (D) Simon W. Pridgeon 1,3,4 \\ ${ }^{1}$ Cairns Hospital, Clinic of Surgery, Cairns, Queensland, Australia \\ 2 Griffith University School of Medicine, Gold Coast, Queensland, Australia \\ ${ }^{3}$ Northern Urology, Cairns, Queensland, Australia \\ 4James Cook University, College of Medicine and Dentistry, Cairns, Queensland, Australia
}

\section{What's known on the subject? and What does the study add?}

Transurethral resection of the prostate (TURP) is the most common surgical treatment method for urinary symptoms secondary to benign prostatic hyperplasia. However, international guidelines suggest using other surgical treatments for larger prostate glands. These other treatments are not universally available and, therefore, TURP may still be the most viable option in some settings. This study assesses the outcomes of TURP in larger glands compared with TURP in smaller glands.

\begin{abstract}
Objective: This study describes the peri-operative results, safety, and functional outcomes of transurethral resection of the prostate (TURP) performed in men with benign prostatic hyperplasia [or hypertrophy; (BPH)] and a prostate gland volume $\geq 100 \mathrm{cc}$.

Materials and Methods: A retrospective analysis of a cohort of patients undergoing TURP at a single institution over four years was undertaken. Patients with known prostate cancer were excluded. Clinical outcomes were between men with a prostate volume of $\geq 100$ cc and men with a prostate volume $<100 \mathrm{cc}$. Functional outcomes were assessed by defining a series of measurable post-operative "lower urinary tract symptoms (LUTS) events" and comparing the time-to-event profile using a Kaplan-Meier estimator.

Results: Out of a total of 238 men who underwent TURP for BPH during the study period, 72 had a prostate volume $\geq 100$ cc (30\%). Baseline demographics were similar to the group of patients with a prostate volume $<100 \mathrm{cc}$. Patients with large prostates had a significantly longer mean operating time ( 56 vs 98 minutes, $p<0.0001$ ). The peri-operative complication profile and post-operative complication rate were similar between the two groups. During a median follow-up period of 27 months (range, 2-54 months), no difference in LUTS events-free survival was observed ( $p=0.93$ ). Conclusion: Our results show that TURP can be safely performed in patients with large prostate glands ( $\geq 100 \mathrm{cc}$ ). Although operating times were longer in the large prostate group, this did not significantly affect the complication rate nor compromise a good functional outcome.
\end{abstract}

Keywords: Benign prostatic hyperplasia, transurethral resection of the prostate, bladder outlet obstruction

\section{Introduction}

Transurethral resection of the prostate (TURP) remains one of the most commonly used methods of surgical management for men with obstructive lower urinary tract symptoms (LUTS) due to benign prostatic hypertrophy [hyperplasia; (BPH)]. The development of numerous, novel surgical techniques has meant the proportion of TURP procedures performed for BPH is decreasing (1). However, TURP remains the operative standard that all current techniques are measured against (2).

Correspondence: Munad Khan MD, Cairns Hospital, Clinic of Surgery, Cairns, Queensland, Australia

Phone: -07 42260000 E-mail: munad.khan@gmail.com ORCID-ID: orcid.org/0000-0002-4140-1500

Received: 29.11.2020 Accepted: 21.02.2021

Cite this article as: Khan M, Nesbitt AL, Loganathan A, Antoniou S, Evans G, Smith P, Pridgeon SW. Comparing Outcomes of Transurethral Resection of the Prostate in Men with Greater Than or Less Than 100 cc Prostate Volume: A Single-Centre Study. J Urol Surg 2021;8(2):92-97.

๑Copyright 2021 by the Association of Urological Surgery / Journal of Urological Surgery published by Galenos Publishing House. 
Improvements in medical therapies for LUTS have meant that surgical treatment can often be delayed $(3,4)$. As a result, many patients are presenting with refractory LUTS and large prostate volumes. Although no upper size limit has been documented for TURP resection, current international guidelines suggest using from 80 to $100 \mathrm{cc}$ as the volume at which consideration should be given to TURP alternatives, such as open prostatectomy or endoscopic laser enucleation $(5,6)$. Such recommendations, along with the inherent risks of long transurethral resection times, have partly led to novel techniques to treat large prostate glands endoscopically (7). Despite these developments, newer techniques, such as the holmium laser enucleation of the prostate, are not universally available across all urology departments. These techniques are often unavailable, including their high initial overhead cost and a difficult learning curve for the surgeon $(8,9)$. Furthermore, therapies such as greenlight laser photoselective vaporisation of the prostate (PVP) still entails a risk of conversion to TURP, highlighting the importance of a good TURP technique for urologists. Our study describes the safety and functional outcomes of performing TURP for large prostate glands.

\section{Materials and Methods}

\section{Patient Population}

Following ethical approval from the Far North Queensland Human Research Ethics Committee (EC00157), we conducted a de-identified retrospective study at our institution of all patients treated with TURP for BPH over four years from March 2014 to July 2018. All patients undergoing TURP were identified; patients with a preoperative prostate cancer diagnosis were excluded from analyses.

Two patient subgroups were established based on the preoperative prostate volume. Measurements were obtained from imaging studies using ultrasound (transabdominal or transrectal), computerised tomography, or magnetic resonance imaging. The two groups were defined by a prostate volume $<100$ cc (group 1) versus $\geq 100$ cc (group 2).

\section{Surgical Procedure}

All patients underwent TURP using either a bipolar or monopolar energy source. Bipolar TURP was performed using a $26 \mathrm{ch}$ continuous flow Olympus resectoscope sheath (Olympus-Europa SE \& Co. Hamburg, Germany) using a Gyrus ACMI PK Superpulse System energy source (Gyrus Medical Inc., Minnesota, USA). Monopolar TURP was performed with a Storz 26 ch continuous flow resectoscope sheath (Karl-Storz - Endoskope, Tuttlingen, Germany) and a Valley Lab Force FX' ${ }^{\mathrm{TM}}$ energy source (Valley Lab Inc. Boulder, Colorado USA). Bipolar TURP was the preferred modality. Monopolar TURP was used when the bipolar equipment was unavailable. Procedures were performed under general or spinal anaesthesia at the discretion of the anaesthetist. Postprocedure, all patients had a three-way 22 French catheter that was routinely removed on post-operative day 2 . All patients were assessed with pre-operative urine culture two weeks before surgery. All infections were treated before surgery. Patients with indwelling urinary catheters were admitted 24 hours before surgery for intravenous antibiotics and a catheter change. Perioperative antibiotic prophylaxis was administered according to local recommendations.

\section{Variables}

A computerised database was created to capture patient demographic, clinical and pathological data regarding their pre-operative, peri-operative and post-operative results using electronic hospital records. Post-discharge complications were captured using local electronic records and electronic records used by all public hospitals in Queensland.

\section{Outcomes}

Patients were routinely followed up between six and eight weeks after hospital discharge. Patients who had no residual bothersome LUTS were discharged at this time point. The need for ongoing follow-up was at the discretion of the consulting clinician. Patients who failed to void successfully post-operatively were discharged with a catheter in situ and routinely returned for catheter removal after two weeks. Postoperative results regarding functional analysis were collected according to the occurrence of "LUTS events" (Table 1). The timing of occurrence of LUTS events was also documented and plotted on a time-to-event curve.

\section{Statistical Analysis}

Statistical analysis of basic demographic, clinical and pathological data and the construction of time-to-event curves

Table 1. Descriptive demographic characteristics of 238 patients treated with transurethral resection of the prostate (TURP) $(<100 \mathrm{cc}$ or $\geq 100 \mathrm{cc})$

\begin{tabular}{|l|l|l|}
\hline Demographic & $\begin{array}{l}<100 \text { cc } \\
\text { Group 1 }\end{array}$ & $\begin{array}{l}\geq 100 \text { cc } \\
\text { Group 2 }\end{array}$ \\
\hline N (total) & $166(70 \%)$ & $72(30 \%)$ \\
\hline $\begin{array}{l}\text { Mean (median; range) age, } \\
\text { years }\end{array}$ & $\begin{array}{l}71.2 \\
(71 ; 49-89)\end{array}$ & $\begin{array}{l}73.2 \\
(72 ; 58-89)\end{array}$ \\
\hline $\begin{array}{l}\text { Mean (median; range) prostate } \\
\text { volume, cc }\end{array}$ & $\begin{array}{l}54.0 \\
(51 ; 12-98)\end{array}$ & $\begin{array}{l}138.4 \\
(130 ; 100-269)\end{array}$ \\
\hline $\begin{array}{l}\text { Preoperative catheter } \\
\text { dependence }\end{array}$ & $81(49 \%)$ & $40(55 \%)$ \\
\hline $\begin{array}{l}\text { Preoperative combination } \\
\text { 5-alpha reductase inhibitor } \\
\text { and alpha blocker use }\end{array}$ & $75(45 \%)$ & $\begin{array}{l}48(66 \%) \\
(p=0.003)\end{array}$ \\
\hline $\begin{array}{l}\text { Previous TURP } \\
\text { TURP: Transurethral resection of the prostate }\end{array}$ & $8(11 \%)$ \\
\hline
\end{tabular}


were performed using GraphPad Prism $8^{\circledR}$. Where reported, a two-sided t-test was used to compare the two groups. LUTS events-free survival curves were compared using the logrank Mantel-Cox test. A $p$-value of $<0.05$ indicated statistical significance.

\section{Results}

\section{Baseline Characteristics}

A total of 296 patients underwent a TURP procedure during the study period. Overall, 219 patients (74\%) had a prostate volume $<100$ cc (group 1) and 77 patients (26\%) had a prostate volume $\geq 100$ cc (group 2). A pre-operative diagnosis of prostate cancer was documented in 58 patients. Therefore, 238 patients were included in the final analysis, with 166 patients (70\%) and 72 patients (30\%) in groups 1 and 2, respectively. Basic demographic data from our cohort are outlined in Table 1. The only significant demographic difference between the two groups was that a greater proportion of patients in group 2 was prescribed a 5-alpha-reductase inhibitor pre-operatively than group 1 (66\% vs 45\%). Peri-operative data are shown in Table 2. Group 2 had a significantly longer operating time with a greater volume of tissue resected. The haemoglobin levels measured on the first post-operative day showed a more considerable mean decrease in group $2(21.8 \mathrm{~g} / \mathrm{dL})$ than group $1(10.5 \mathrm{~g} / \mathrm{dL})$. Incidental prostate cancer was detected on histopathology in 28 men (16\%) in group 1 compared with six men (8\%) in group 2.

\section{Safety}

Overall complications were similar in both groups $(26.4 \%$ vs 25.9\%). Figure 1 shows the number of complications described using the Clavien-Dindo classification. Despite a more considerable measured decrease in post-operative haemoglobin for group 2, there was no difference in the transfusion rate

\begin{tabular}{|c|c|c|}
\hline Peri-operative characteristic & $\begin{array}{l}<100 \text { cc } \\
\text { Group } 1\end{array}$ & $\begin{array}{l}\geq 100 \text { cc } \\
\text { Group } 2\end{array}$ \\
\hline Bipolar TURP & $93 \%$ & $91 \%$ \\
\hline Spinal anaesthesia & $38 \%$ & $54 \%$ \\
\hline Mean operating time (mins) & 56 & $\begin{array}{l}98 \\
(p<0.0001)\end{array}$ \\
\hline $\begin{array}{l}\text { Mean (median; range) } \\
\text { resection weight }(\mathrm{g})\end{array}$ & $14.8(13 ; 0.5-58)$ & $45.3(43 ; 3-161)$ \\
\hline $\begin{array}{l}\text { Mean (median; range) post- } \\
\text { operative length of stay } \\
\text { (days) }\end{array}$ & $2.8(2 ; 1-10)$ & $2.9(2 ; 2-14)$ \\
\hline $\begin{array}{l}\text { Mean drop in post-operative } \\
\text { haemoglobin }(\mathrm{g} / \mathrm{dL})\end{array}$ & 10.5 & 21.8 \\
\hline
\end{tabular}

between the two patient groups ( $1 \%$ vs $2 \%$ ) (Table 3 ). A summary of post-operative complications is shown in Table 3.

\begin{tabular}{|l|l|l|}
\hline \multicolumn{3}{|l|}{ Table 3. Summary of post-operative complications } \\
\hline Complication & $\begin{array}{l}<100 \text { cc } \\
\text { Group 1 } \\
\mathbf{n = 1 6 6}\end{array}$ & $\begin{array}{l}>100 \text { cc } \\
\text { Group 2 } \\
\mathbf{n = 7 2}\end{array}$ \\
\hline Transfusion rate & $4(2 \%)$ & $1(1 \%)$ \\
\hline Unexpected ICU admission & $2(1 \%)$ & $2(3 \%)$ \\
\hline Sepsis & 0 & 0 \\
\hline Cardio-pulmonary complications & $2(1 \%)$ & $4(5 \%)$ \\
\hline TUR syndrome & $1(0.5 \%)$ & 0 \\
\hline Bladder perforation & $2(1 \%)$ & 0 \\
\hline $\begin{array}{l}\text { Re-presentation to ED } \\
\text { (no admission required) }\end{array}$ & $17(10 \%)$ & $6(8 \%)$ \\
\hline Re-admission within 28 days & $10(6 \%)$ & $5(7 \%)$ \\
\hline Return to theatre & $4(2 \%)$ & $1(1 \%)$ \\
\hline Death within 28 days & $1(0.5 \%)$ & 0 \\
\hline ICU: Intensive care unit, TUR: Transurethral resection, ED: Emergency department \\
\hline
\end{tabular}

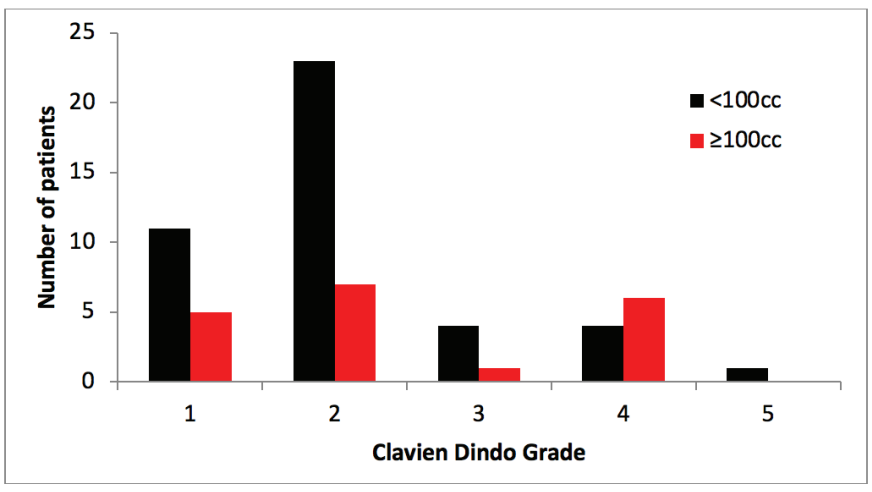

Figure 1. Peri-operative and post-operative complications in 238 men undergoing TURP for BPH

TURP: Transurethral resection of the prostate, BPH: Benign prostatic hyperplasia

\section{Functional Outcomes}

All patients underwent an in-patient trial without a catheter during their peri-operative hospital stay. Also, 129 (77\%) patients in group 1 (prostate volumes <100 cc) successfully voided and were discharged home without a catheter compared with 61 patients (84\%) in group 2. Of the 121 patients who were catheter-dependent pre-operatively, 103 (85\%) were voiding spontaneously at the sixth post-operative week with 67 (82\%) and $36(90 \%)$ patients in groups 1 and 2, respectively, who were catheter-dependent pre-operatively becoming catheterfree. With a median follow-up time of 27 months (range, 2-54 months), LUTS events as described in Table 1 were observed in $35(21 \%)$ vs $16(22 \%)$ for patient groups 1 and 2 . The time to LUTS events is shown in Figure 2. The Kaplan-Meier LUTS events-free survival curves were not different between the two 


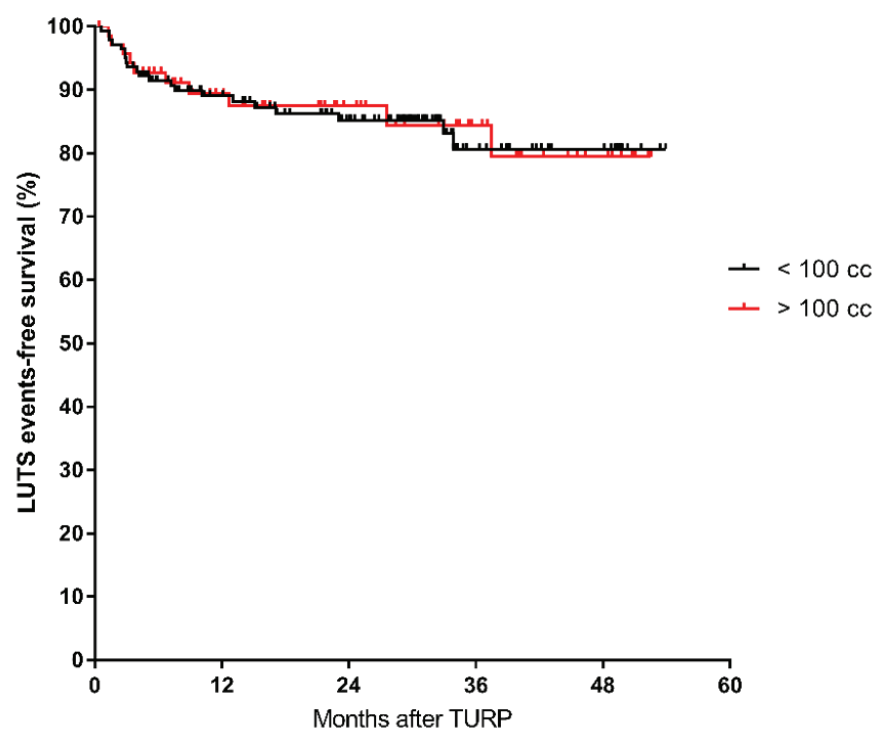

Figure 2. Freedom from LUTS events following TURP in men with prostate volumes $<100 \mathrm{cc}$ compared with men with prostate volumes $\geq 100 \mathrm{cc}$

TURP: Transurethral resection of the prostate, LUTS: Lower urinary tract symptoms

groups ( $\mathrm{p}=0.93$; log-rank Mantel-Cox test). During the followup period, a re-do TURP was performed in three (2\%) patients of the $<100$ cc group compared with two (3\%) patients of the $\geq 100$ cc group.

\section{Discussion}

To our knowledge, our study contains the largest number of patients undergoing TURP for LUTS with a prostate gland $\geq 100$ cc in volume $(n=72)$, comprising $30 \%$ of our total cohort of men undergoing TURP for BPH. The selection of $100 \mathrm{cc}$ as the definition of a large prostate was based on the largest volume used to make recommendations from international guidelines. We chose to compare this size directly with the standard "small" gland TURP since, for this latter group TURP remains the current standard of care.

TURP is a well-established surgical treatment for men with symptomatic BPH. Robust long-term data exists supporting the efficacy of TURP that has not yet been replicated for more recently developed techniques (10). Despite this, the support for TURP in large prostate glands is less compelling. Although there is no defined upper limit of prostate size for the use of TURP, urological guidelines recommend considering other forms of surgical treatment in men with large prostate volumes. The European Association of Urology recommends that urologists should offer endoscopic enucleation or open prostatectomy to treat moderate-to-severe LUTS in men with a prostate volume $>80 \mathrm{~mL}$ (5). This recommendation is supported by available outcome data. However, the higher complication rate of open prostatectomy and the learning curve associated with endoscopic enucleation procedures may be limitations in applying this recommendation. The United Kingdom's National Institute for Health and Care Excellence guidelines on LUTS in men do not set an upper limit for TURP. However, they recommend only offering open prostatectomy as an alternative to endoscopic procedures to men with prostate sizes estimated to be larger than 80 grams. This recommendation is based on expert opinion, and the prostate size cut-off was set from studies that used inclusion criteria from 70 to 100 grammes (11). The 2010 American Association of Urology guidelines (6) on the management of BPH reported a prostate size of $>100$ grammes as a criterion for considering the use of transurethral enucleation or laser vaporisation procedures. The 2018 AUA guidance recommends that clinicians consider open, laparoscopic or robotic simple prostatectomy for men with very large prostates with no specific size cut-off (12). However, many surgical treatment options, including bipolar TURP, greenlight laser surgery, and prostatic artery embolisation, have all been shown to be safe and efficacious in very large glands with short-to-medium-term follow-up (13-15).

With regard to the safety profile of the TURP procedure, despite the longer operating times (98 vs 56 mins) and a larger decrease in post-operative haemoglobin (21.8 vs $10.5 \mathrm{~g} /$ $\mathrm{dL}$ ), the overall complication rate did not differ between the two groups in our study. This was comparable to the expected complication rate in the literature (16). When distributed across the Clavien-Dindo classification, there was a higher proportion of grade 4 complications in the large prostate group than the $<100$ cc prostate group ( $8.3 \%$ vs $2.4 \% ; p=0.03$ ). Most of these complications were exacerbations of pre-existing cardiorespiratory medical comorbidities that were not matched between the two groups. Despite the higher incidence of grade 4 complications, overall hospital stays and readmission rates were equivalent between the two groups. Unique complications, such as urinary tract infection, TUR syndrome and transfusion requirement, were evenly matched and similar to those expected from international guidelines (5).

From a functional perspective, the two groups were evenly matched regarding achieving independence from catheterisation irrespective of prior catheterisation status. A substantial proportion of our total patient cohort was catheter-dependent before undergoing TURP (50.8\%). Our decision to evaluate "LUTS events" was designed to focus on combined clinically orientated functional outcomes post-TURP. Although IPSS scores may be helpful in objectively determining the improvement in symptoms after BPH treatment, symptom scores may not necessarily drive the need for further investigations and treatments or alter clinicians' decisions to discharge patients back to the care of community practitioners. Our definitions of LUTS events after BPH surgery (Table 1) aimed to represent comprehensive, 
measurable clinical outcomes that were highly relevant to BPH surgery and reflect objective functional efficacy and indicate patients' degree of bothersome symptoms that require further investigations or treatments. In addition, given the high proportion of catheter-dependent patients before TURP, the lack of validity of pre-operative IPSS scores in patients with indwelling catheters would eliminate over half of our patients from comparative analysis. The overall shape of the timeto-event curve (Figure 2) showed no statistically significant difference between the two groups, and the incidence of LUTS events as defined in Table 1 was consistent with the accepted event complication rate, such as bladder neck contracture, urethral stricture and re-do TURP in contemporary series (17).

The proportion of patients with incidental prostate cancer demonstrated was double in the $<100$ cc group compared with the $\geq 100$ cc group, although this finding was not statistically significant $(p=0.09)$. This trend is likely to be due to reduced sampling of the peripheral zone in TURP for the larger glands compared with small glands. The incidental detection rate supports the added benefit of TURP in obtaining histological information compared with vaporisation techniques or prostatic artery embolisation.

\section{Study Limitations}

Our study has some important limitations. Given the retrospective design of the study, data collection was dependent on accurate documentation of clinical events. Selection bias is always a limitation of retrospective studies. However, as our two comparative groups were purely based on prostate size, this bias is reduced. In addition, we do not offer any other form of endoscopic outflow surgery in our department (e.g. laser enucleation, laser PVP or UroLift). During the study period, only two patients in our unit underwent simple open prostatectomy (data not shown); both patients had prostate volumes in $>350$ cc and were deemed unsuitable for endoscopic management after endoscopic assessment. Therefore, except for these two patients, all men requiring outflow surgery for BPH underwent the same treatment modality. The documentation of LUTS events has relied on patients presenting to our institution or regional hospitals and appropriate referrals to our unit from community practitioners. This introduces the potential for under-reporting of such events; however, our institution has the only public urology service in the region.

\section{Conclusion}

In the absence of available prospective evidence on this topic, we believe our study supports the use of TURP in large prostate glands when undertaken by an experienced surgical team performing a high caseload. TURP still has a current role in treating LUTS secondary to BPH, even with the variety of minimally invasive techniques available to surgeons. Although international guidelines for the use of TURP in large glands are conservative, we believe that TURP can still be safely offered to such patients with the expectation of a good functional outcome.

\section{Ethics}

Ethics Committee Approval: Following ethical approval from the Far North Queensland Human Research Ethics Committee (EC00157), we conducted a de-identified retrospective study at our institution of all patients treated with TURP for BPH over four years from March 2014 to July 2018.

Informed Consent: Retrospective study.

Peer-review: Externally peer-reviewed.

\section{Authorship Contributions}

Surgical and Medical Practices: A.L., S.A., G.E., P.S., Concept: M.K., A.L.N., S.W.P., Design: A.L., S.A., G.E., P.S., Data Collection or Processing: M.K., A.L.N., S.W.P., Analysis or Interpretation: M.K., A.L.N., S.W.P., Literature Search: A.L., S.A., G.E., P.S., Writing: M.K., A.L.N., S.W.P.

Conflict of Interest: No conflict of interest was declared by the authors.

Financial Disclosure: The authors declare that they have no relevant financial.

\section{References}

1. Malaeb BS, Yu X, McBean AM, Elliott SP. National trends in surgical therapy for benign prostatic hyperplasia in the United States (2000-2008). Urology 2012;79:1111-1116.

2. Jones C, Hill J, Chapple C; Guideline Development Group. Management of lower urinary tract symptoms in men: summary of NICE guidance. BMJ 2010;340:2354.

3. McConnell JD, Bruskewitz R, Walsh P, Andriole G, Lieber M, Holtgrewe $H \mathrm{~L}$, Albertsen P, Roehrborn CG, Nickel JC, Wang DZ, Taylor AM, Waldstreicher $J$. The effect of finasteride on the risk of acute urinary retention and the need for surgical treatment among men with benign prostatic hyperplasia. Finasteride Long-Term Efficacy and Safety Study Group. N Engl J Med 1998;338:557-563.

4. Roehrborn CG, Bruskewitz R, Nickel JC, McConnell JD, Saltzman B, Gittelman MC, Malek GH, Gottesman JE, Suryawanshi S, Drisko J, Meehan A, Waldstreicher J; Proscar Long-Term Efficacy and Safety Study Group. Sustained decrease in incidence of acute urinary retention and surgery with finasteride for 6 years in men with benign prostatic hyperplasia. J Urol 2004;171:1194-1198.

5. Gratzke C, Bachmann A, Descazeaud A, Drake MJ, Madersbacher S, Mamoulakis C, Oelke M, Tikkinen KAO, Gravas S. EAU Guidelines on the Assessment of Non-neurogenic Male Lower Urinary Tract Symptoms including Benign Prostatic Obstruction. Eur Urol 2015;67:1099-1109.

6. McVary KT, Roehrborn CG, Avins AL, Barry MJ, Bruskewitz RC, Donnell RF Foster HE Jr, Gonzalez CM, Kaplan SA, Penson DF, Ulchaker JC, Wei JT. Update 
on AUA guideline on the management of benign prostatic hyperplasia. J Urol 2011;185:1793-1803.

7. Tan A, Liao C, Mo Z, Cao Y. Meta-analysis of holmium laser enucleation versus transurethral resection of the prostate for symptomatic prostatic obstruction. Br J Surg 2007;94:1201-1208.

8. Kuntz RM. Current role of lasers in the treatment of benign prostatic hyperplasia (BPH). Eur Urol 2006;49:961-969.

9. Robert G, Cornu JN, Fourmarier M, Saussine C, Descazeaud A, Azzouzi AR, Vicaut $E_{1}$ Lukacs $B$. Multicentre prospective evaluation of the learning curve of holmium laser enucleation of the prostate (HoLEP). BJU Int 2016;117:495-459.

10. Reich O, Gratzke C, Stief CG. Techniques and long-term results of surgical procedures for BPH. Eur Urol 2006;49:970-978.

11. National Institute for Health and Care Excellence. Lower urinary tract symptoms in men: management 2010. Available from: www.nice.org.uk/ guidance/cg97.

12. Foster HE, Barry MJ, Dahm $P$, Gandhi MC, Kaplan SA, Kohler TS, Lerner LB, Lightner DJ, Parsons JK, Roehrborn CG, Welliver C, Wilt TJ, McVary KT. Surgical Management of Lower Urinary Tract Symptoms Attributed to Benign Prostatic Hyperplasia: AUA Guideline. J Urol 2018;200:612-619.
13. Mamoulakis C, Ubbink DT, de la Rosette JJ. Bipolar versus monopolar transurethral resection of the prostate: a systematic review and metaanalysis of randomized controlled trials. Eur Urol 2009;56:798-809.

14. Valdivieso R, Hueber PA, Meskawi M, Belleville E, Ajib K, Bruyere F, Te $A E$, Chughtai $B$, Elterman D, Misrai V, Zorn KC. Multicentre international experience of 532-nm laser photoselective vaporization with GreenLight XPS in men with very large prostates. BJU Int 2018;122:873-878.

15. Ray AF, Powell J, Speakman MJ, Longford NT, DasGupta R, Bryant T, Modi S, Dyer J, Harris M, Carolan-Rees G, Hacking N. Efficacy and safety of prostate artery embolization for benign prostatic hyperplasia: an observational study and propensity-matched comparison with transurethral resection of the prostate (the UK-ROPE study). BJU Int 2018;122:270-282.

16. Rassweiler J, Teber D, Kuntz R, Hofmann R. Complications of transurethral resection of the prostate (TURP)--incidence, management, and prevention. Eur Urol 2006;50:969-979.

17. Mamoulakis C, Schulze M, Skolarikos A, Alivizatos G, Scarpa RM, Rassweiler $\mathrm{JJ}$, de la Rosette JJ, Scoffone CM. Midterm results from an international multicentre randomised controlled trial comparing bipolar with monopolar transurethral resection of the prostate. Eur Urol 2013;63:667-676.

\section{LUTS events:}

Failure to void / need for long term catheterization (urethral or supra pubic) Need for long term intermittent self-catheterisation

LUTS requiring long term medical therapy eg anticholinergic

LUTS requiring further investigations eg cystoscopy / urodynamics

Re-referral to the department for evaluation of LUTS

Need for repeat TURP

Need for stricture management

Episode of urinary retention

Formation of bladder stones 